\title{
A Constitutional Bill of Rights - The Canadian Experience
}

Terence G. Ison

Osgoode Hall Law School of York University

Source Publication:

Modern Law Review. Volume 60, Issue 4 (1997), p. 499-512.

Follow this and additional works at: https://digitalcommons.osgoode.yorku.ca/scholarly_works (c) (1) $(9)$

This work is licensed under a Creative Commons Attribution-Noncommercial-No Derivative Works 4.0 License.

\section{Recommended Citation}

Ison, Terence G. "A Constitutional Bill of Rights - The Canadian Experience." Modern Law Review 60.4 (1997): 499-512.

This Article is brought to you for free and open access by the Faculty Scholarship at Osgoode Digital Commons. It has been accepted for inclusion in Articles \& Book Chapters by an authorized administrator of Osgoode Digital Commons. 


\section{REVIEW ARTICLE}

\section{The Reasoning Game: Some Pragmatic Suggestions}

Allan C. Hutchinson*

Cass Sunstein, Legal Reasoning And Political Conflict, New York: Oxford University Press, 1996, 220 pp, hb \$25.00.

It seems like whole libraries or, at least, large tracts of them, have been written about the mysterious concept and practice of legal reasoning. Although there has been much toing-and-froing around the matter, the common wisdom still prevails that, as Chief Justice Coke put it in the 17 th century, there is an 'artificial Reason and Judgment of Law which requires long Study and Experience before a Man can attain to the Cognizance of it.' By this, it is usually meant that law has its own special form of reasoning that distinguishes it in some important way from other disciplines and other forms of reasoning (economic, scientific, logical, political, sociological, etc). Like all reasoning, legal reasoning is a process of argumentation by which it is possible to infer or move from one already accepted proposition to another that has yet to be accepted. Of course, everyone agrees that legal reasoning is distinctive to the extent that it works upon a particular set of materials (cases and statutes), is framed in a professional jargon (eg, stare decisis and obiter dicta), and is engaged in by a restricted community of professionals (lawyers and judges). However, that is as far as any agreement goes. As central as it is to the whole legal enterprise, the precise identity or nature of legal reasoning remains elusive; it defies simple classification or easy analysis. As such, much

\footnotetext{
Osgoode Hall Law School, York University, Toronto. I am grateful to Remy G. Boghossian and Jim Smith for their research and assistance.
} 
contemporary jurisprudence remains fixated with clarifying and justifying the operation and status of legal reasoning.

While most lawyers and judges continue to insist that 'legal reasoning has a logic of its own ... [whose] structure fits it to give meaning to ambiguity,' ${ }^{1}$ I maintain that such a formalistic position is both untenable and unnecessary. Shorn of its legal nomenclature and doctrinal dressing, legal reasoning is simply a general and non-specific style of reasoning which lawyers have colonised and at which judges have become particularly adept; the claim that legal reasoning is special not only in its formal attributes, but also in its ability to arrive at substantively better and worse answers cannot be sustained. As a normative exercise, it is not an empirical matter of truth or falsity: legal reasoning is less a demonstration of logical necessity and more a practice of human justification. More particularly, legal reasoning is a mode of playful and rhetorical activity. This insight has been latched upon as the basis of a neo-pragmatic revival in jurisprudence. However, as exemplified in the esteemed work of Cass Sunstein, these efforts to construe law and adjudication as a practical activity flatter, but only to disappoint: the new nonformalist packaging belies the old formalist commitment. In contrast, I will offer a different understanding of legal reasoning that is thoroughly pragmatic in ambition and elaboration. I insist that adjudication, like much of life itself, is best understood as a playful attempt by judges to engage in a language game that seeks to regulate social life. By depicting adjudication as a non-formalist game of infinite proportions, my account seeks to explain and evaluate adjudication in such a way that it captures 
its sense as a peculiar professional practice (in which it stands as something of its own thing) and as a profoundly political undertaking (in which it is organically related to the larger context of society). In this way, it might be possible to realise that law is not so much a site that is located aside or away from ordi nary life and that adjudication is not so much an activity that can be appreciated as separate from ordinary livi ng: law is a part of, not apart from, life and adjudication represents one site and way of playing the game of life. ${ }^{2}$

The essay is divided into six parts. First, I introduce the basic orientation of Sunstein's pragmatic accou nt of law and his emphasis on analogical reasoning and incompletely theorised agreements as the keys to legal casuistry. In the next three short sections, I criticise the limitations of Sunstein 's account analogical reasoning hides rather than does away with the historical values and social ideas that energise the law's operation; incompletely theorised agreements are not so much under-theorised as under-agreed-to to do the work asked of them; and the fixed precedential points that anchor legal reasoning allow much more movement than suggested. The last two sections offer a deconstructive account of 'play' that better captures the general practice of legal reasoning at large. Resisting the tendency to transcendentalise or divinise notions like 'play' by turning them into metaphysical entities, I treat legal reasoning as playful moves in a pragmatic game and trace the implications of this non-formalist approach for the practical performance and theoretical justification 
of the judicial craft. In short, I want to insist that, in law's language game, there is nothing to ground play, but more play: there is no final or privileged way to play law's game that explains and grounds all others that is not itself a game.

\section{The pragmatic gambit}

Eschewing the hubristic aspirations of natural lawyers and other formalists, a new breed of pragmatists have sought to re-valorise law and adjudication as a professional practice in which practical people pursue practical ends through practical means. ${ }^{3}$ As a 'back to basics' movement, legal neo-pragmatism is not so much a philosophy or methodology, but more a way of professional life: it nurtures an existential ethic of inquiry rather than inculcates a catechism of substantive outcomes. By treating truth and correctness as experiential and experimental rather than apodictic and apocalyptic, adjudication comes to be understood as involving nurtured prudence, not revealed knowledge. While law remains a noble calling under such a perspective, its practitioners are more artisans than artists and more technicians than grand theorists; Cardozo, Holmes, Learned Hand and Llewellyn are their heroes. Extolling the practical virtues of intellectual self-discipline and traditional craft, legal pragmatists conceive of law as being much more playful and practice-based than other contemporary jurists. However, while appreciating that adjudication is a kind of game, they do not have the confidence of their convictions in pushing 
through on the subversive implications of their insight that legal reasoning is all about 'making moves' in a finite game of infinite possibilities.

Cass Sunstein is at the forefront of this pragmatist revival. In Legal Reasoning and Political Conflict, his professed ambition is to restore the fading, but vital faith in the worth and viability of the legal craft. While legal reasoning is a rule-based practice, law is not exhausted by the existence or application of rules; rules are an important resource, but they do not themselves fix the distinguishing characteristic of legal thinking because 'ideal justice outstrips rules; it adapts the account to the particulars of the case' ( $\mathrm{p}$ 135). More fundamentally, law is about reason-giving as much as it is about decision-making or rule-application. According to Sunstein, law devlops by self-conscious attention to its argumentative structure as much as by a formal consistency with substantive outcomes. Nevertheless, rules are important because they 'sharply discipline the territory over which argument can occur' (p 191). For Sunstein, the life of the law is the (ana)logic of its own experience; there is method in the seeming madness of legal reasoning that is peculiarly and especially its own. Lawyers should not be embarrassed by their instinctive habits of mind or argumentative routines, but shou ld recognise and celebrate their pragmatic force and dispositive power. While he treasures coherence, Sunstein believes its demands are satisfied by much less than a snug fit between the almost infinite range of concrete propositions and their controlling abstract principles: law is neither wholly reducible to unadulterated politics nor wholly inflatable into pure integrity. Under this pragmatic calling, the judge is bound by an official tradition of legal 
reasoning, but has room to experiment within its confines. While politics are always involved in legal disputations, the judge can remain agnostic and act in a uniquely and proudly legal way: law might be political, but it is not merely political.

For Sunstein, therefore, the special method of the law is to be found in its traditional reliance on analogical reasoning. While analogical reasoning is pervasive in law and everyday life, 'analogical reasoning is the key to legal casuistry' ( $\mathrm{p} 32$ ) and 'lies at the heart of legal thinking and for good reason' (p 99); it has a distinctive structure and faces distinctive constraints. Because analogical reasoning imposes a certain discipline, there is less need for a widespread moral or political consensus. Indeed, Sunstein's reliance on incompletely theorised agreements seems to have virtually eliminated the need for any agreement on such issues. As the most familiar means of legal reasoning, analogical reasoning ru ns neither inductively from particulars to generalities nor deductively from generalities to particulars, but moves from particulars to particulars: analogical reasoning is not syllogistic and scientific in form and function, but is practical and probabilistic. The beauty of legal reasoning is that it allows lawyers and judges to engage with political and moral values without reducing law to an open-ended ideological debate and without collapsing it into some other field of knowledge, like politics or economics. Large-scale debate about controversial issues is avoided by the fact that legal reasoning functions by relying on 'a set of practices, conventions, and outcomes ... [that] makes legal interpretation possible ... and sharply 
constrains legal judgment' (p 13). This legal culture of syntactic and substantive principles places off-limits certain deep conflicts over the right and good as being too ideological and unsuited to legal resolution; 'the lawyer's questions have everything to do with constraints of competence and role' $\{\mathrm{p}$ 34) and 'there can be a real difference betwe the legally correct outcome and the morally correct outcome' (p 92).

Sunstein's account of how analogical reasoning works is fairly uncontroversial but it is the claims that he makes for its operation that are decidedly controversial in character. He highlights four steps in the analogical process: (I) fact pattern has certain characteristics A, B, and C; (2) fact pattern $\mathrm{Y}$ differs from $\mathrm{X}$ i $\mathrm{n}$ some; respects, but shares certain other characteristics $\mathrm{A}, \mathrm{B}$, and $\mathrm{C}$; (3) the law treats $\mathrm{X}$ ir a certain way; and (4) because fact pattern $\mathrm{Y}$ shares certain characteristics with fac1 pattern $\mathrm{X}$, the law should treat fact pattern $\mathrm{Y}$ in the same way. Obviously, the application of such an analogical process involves normative judgments about relevance and valence in terms of the similarities and differences between fac1 patterns. However, according to Sunstein, the legitimacy and genius of analogical reasoning as a legal practice is that it 'will impose a certain discipline ... [suet that] there can be a real difference between the legally correct outcome and the; morally correct outcome; the difference lies in the fact that analogies will operate; as entirely "fixed points" in legal reasoning, whereas many of these are revisabk in morality' (pp 91-92). Moreover, in understanding analogical reasoning in thi5 way as the key manoeuvre in the judicial repertoire of legal moves, judges 'need not, much of the time, 
attempt to say much about large-scale social controversies' (p 195). In this important sense, therefore, analogical reasoning is different from and preferable to other forms of legal argumentation, such as resort to abstrac1 theories of 'wealth maximization' or 'natural rights', because it operates at a mud more concrete and modest level and in a much less theoretical and piecemeal way: it does not need to take a stand on such ideological and controversial matters. A5 such, analogical reasoning is the most effective, legitimate and just form of legal argumentation in that it achieves 'principled consistency, a focus on particulars, incompletely theorised judgments and principles operating at a low 01 intermediate level of abstraction' (p 67).

The bulk of Sunstein's monograph is appropriately devoted to a rich series o1 practical illustrations about the operation of analogical reasoning and the legitimacy of incompletely theorised agreements. $\mathrm{He}$ demonstrates an enviably wide and subtle appreciation of the common law. Indeed, the great strength of all his work is the lucid and concrete way in which he makes and defends his jurisprudential claims; jargon is eschewed and Sunstein works hard to keep his discussion accessible to the nonspecialist. However, despite the obvious appeal o1 this pragmatic and relatively playful approach, the new pragmatism tends to be pragmatic in the most non-pragmatic and, at times, almost anti-pragmatic way. Although paying lip-service to the decidedly pragmatic qualities of contextual sensitivity and prudential judgment, Sunstein is far too concerned with discovering and defining The Way Things Really Are. By demonstrating that 'analogical reasoning is the key to legal casuistry' (p 32) 
he enlists pragmatism to complete the formalist campaign of demonstrating that law is a self-sufficient system that can produce correct, determinate, predictable and distinctly legal outcomes. This is a flat denial of the pragmatist's belief that legal reasoning is not really about anything unique or special at all. Indeed, from a more rigorously pragmatic perspective, legal reasoning is what it is and what it is is historically contingent and socially revisable. Legal reasoning is nothing more (and nothing less) than how particular lawyers reason at particular times. While some modes of legal reasoning lend themselves better to some tasks than others, this conclusion entails a contingent evaluation of their practical utility in particular situations. It does not involve fixing 'the nature of legal reasoning' because it has none in any essential 01 lasting sense: there is no neutral or reliable algorithm for legal decision-making or any other kind.

\section{Beyond analogy}

While it is true that the law is much more pragmatic and less analytical than most contemporary theorists pretend or allow, it strains the bounds of credibility to promote analogical reasoning as the underwriter of correct, determinate and distinctly legal operations and outcomes. On the contrary, although analogical reasoning plays an important and frequent role in law's reasoning game, it is thoroughly indeterminate in practice and consequence. Most typically, this indeterminacy will manifest itself where fact pattern $\mathrm{Y}$ has more or less similarities with and differences from fact pattern X. As no two cases are ever entirely the same or different, this 
will occur almost all the time. For example, fact pattern $\mathrm{X}$ might be comprised of characteristics A, B, C, D, and E, but fact pattern Y might possess either A, B, C, and D or A, B, C, D, E, and F. In either case, there is nothing internal to the process of analogical reasoning that can determine whether the existence of one more, less or different characteristic is sufficient to warrant treating fact pattern $\mathrm{Y}$ like fact pattern X or not. Indeed, the addition or subtraction of one characteristic might alter the collective meaning of the other characteristics: without $\mathrm{C}$, the remaining characteristics $\mathrm{A}, \mathrm{B}, \mathrm{D}$, and $\mathrm{E}$ might take on a very different significance and, with $\mathrm{F}$, the characteristics $\mathrm{A}, \mathrm{B}, \mathrm{C}, \mathrm{D}$, and $\mathrm{E}$ might amount to a very different whole. Also, it might happen that in fact pattern $X$, a re-appraisal might suggest that its relevant characteristics were not $\mathrm{A}, \mathrm{B}, \mathrm{C}, \mathrm{D}$, and $\mathrm{E}$, but really were $\mathrm{A}, \mathrm{B}, \mathrm{C}$, and $\mathrm{D}$ or $\mathrm{A}, \mathrm{B}, \mathrm{C}$, D, E, and F. For instance, once it is decided that a car is a 'vehicle' in terms of the rule that there are to be 'no vehicles in the park', whether a person on roller-blades is a 'vehicle' will depend on the presumed or postulated purpose of such a rule is it intended to reduce noise, cut down on traffic, protect the safety of pedestrians, etc?

In almost all circumstances, there will be a pragmatic embarrassment of analogical riches. If good arguments are the touchstone of law and its legitimate functioning, there are simply too many good arguments for the pragmatists' peace of mind. In this situation, while fact pattern $\mathrm{Y}$ has characteristics $\mathrm{A}, \mathrm{B}, \mathrm{C}, \mathrm{D}$, and $\mathrm{E}$, there are two earlier fact patterns $\mathrm{W}$ and $\mathrm{X}$ that were disposed of in entirely opposite ways; 
fact pattern $\mathrm{W}$ has characteristics $\mathrm{A}, \mathrm{B}$, and $\mathrm{C}$ and fact pattern $\mathrm{X}$ has characteristics $\mathrm{C}, \mathrm{D}$, and $\mathrm{E}$. There is no way to compare the relative cogency of the two competing analogical options without resort to some values or principles that are extraneous to the process of analogical reasoning itself. ${ }^{4}$ Yet analogical reasoning does not determine the result; it is only a testing device for the more important political determinations that are made prior to and after analogical testing occurs. At every stage, the judge is obliged to make resort to the values and principles that analogical reasoning is intended to finesse. Analogical reasoning is thereby debilitated by the same weaknesses that afflict a rule-based account of law. In the same way that it is never possible to simply 'follow the rules', because the question of the relevant and precise rule and what following it entails remains irresolvably contestable, it is also not possible to simply engage in analogical reasoning, because the question of the relevant and precise analogy and what following it entails remains irresolvably contestable. Accordingly, in contrast to Sunstein, I do not believe that, in deciding 'whether one case is analogous to another, we need not, much of the time, attempt to say much about large-scale social controversies' (p 195); analogical reasoning hides rather than does away with the historical values and social ideas that energise the law's operation.

For analogical reasoning to be cogent and compelling, there must be sufficient justification to warrant the inference that, because property $\mathrm{X}$ is present in one instance, it is present in another. But there is no way to identify 
or confirm through the logic of analogical argument itself that certain characteristics are present or that any inference are warrantable. This is a matter of imputation, not demonstration. Indeed, analogical reasoning must be complemented and supplemented by resort to what Sunstein is most at pains to avoid what he describes as 'large-scale social controversies' if it is to make any sense at all. Conversely, with recourse to such external values, his formalist-style claims about the 'real difference between the legally correct outcome and the morally correct outcome' ( $\mathrm{p}$ 92) ring hollow. Moreover, because pragmatism is more ad hoc than a priori, any juristic attempt to effect a more programmatic or systematic appeal to political or social values ceases to be pragmatic. Like his pragmatic predecessors, Sunstein fails to provide any guide as to how distinguish good from bad analogical reasoning. On this crucial question, he is left with Levi's inadequate conclusion that the determination of similarity and difference is the function of each judge' and that 'legal reasoning tests constantly whether society has come to see new differences or similarities.'5 While this strikes an agreeable note within a non-formalist approach, it is cold comfort to Sunstein's formalist commitments. In short, while analogical reasoning is an important dimension of legal reasoning, it cannot provide the vital grounding that the new pragmatists suggest.

Unclear about whether analogical reasoning acts as a constraint on law or whether law acts as a constraint on analogical reasoning, Sunstein and other pragmatists are unable to overcome the criticism that the analytical validity of the substantive outcome is not warranted by the analogical 
form of the legal argument. It is not the force of Reason, analogical or otherwise, that determines what is important and relevant in legal decisionmaking, but what is substantively reasonable and contingently acceptable as a matter of practical reason. As such, the determinacy or correctness of legal reasoning is not closed, but open and, therefore, is as much political as it is legal. While there are constraints that exist and are experienced by lawyers and judges, these constraints are less determinate and more revisable than is conceded. Constraints are as re-interpretable as the reasoning that they are intended to constrain. Of course, it is not that there are not better or worse answers or even correct ones, but that 'there is never any "correct legal solution" that is other than the correct ethical and political solution to that legal problem.' 6 Again, that is, of course, 'correct' in the contingent and contextual sense that certain people for certain purposes at a certain time and place are persuaded that it is correct. A resoundingly pragmatic account does not deny the existence of such a standard, but de-stabilises its status and grounding.

\section{Not so fixed}

If Sunstein is to make good on this deficiency, his primary responsibility must be to establish a distinctly legal standard against which to measure the weighting of the various similarities and differences. He maintains that, as judges' convictions about the meaning and importance of certain decisions will warrant a certain priority in constraining the potentially open-ended operation of analogical reasoning, there are certain defining moments or 'fixed 
points' of legal precedent that require judges 'to square current judicial decisions with previous judicial decisions that have stood the test of ti me' ( $p$ 82) and, therefore, 'real constraint on judicial discretion ... comes from precedent' (p 179). For example, the fact that all judges accept that certain cases, such as Brown and Roe, 1 must be incorporated into any proposed theory about the American Constitution emboldens Sunstein to maintain that 'legal reasoning has a distinctive structure and faces distinctive constraints' (p 75). However, while it might be possible to agree on a handful of fixed precedential points, they would be so limited as to be of little practical use: any attempts to enlarge this crucial category sufficiently for it to become practically operative will meet sharp and sectarian political disagreement. Moreover, even though Sunstein acknowledges that such fixed points 'do not speak for themselves, and judgments about their meanings have large creative dimensions' (p 82), it is difficult to understand how Brown or Roe have a settled and shared interpretation capable of providing the necessary direction and force to get analogical reasoning up and running. Both Brown and Roe have been subjected to intense public attempts at interested interpretation and represent a site for the manufacture of meaning as much as an adequate grounding for its resolution. Moreover, as Brown and Roe aptly illustrate, the genesis of these fixed precedential points is to be found in strikingly creative and non-analogical judicial acts that break with existing legal traditions. and reorient the whole legal enterprise. For all his pragmatic protestations, Sunstein's account and defence of analogical reasoning remains profoundly abstruse and rationalistic in the sense that it is unsituated in the material circumstances of 
history and is inured to their political dynamics: 'abstract universality' is ditched, but only to be replaced by 'abstract particularity'. For a pragmatic approach that is supposed to valorise experience and contextuality, there is little appreciation that legal reasoning operates in the real world of historical struggle or of how law does (and does not) change. For Sunstein, the only experience and context that matters is the legal one: the experience of the law is the life of its own (ana)logic. He makes no attempt to place Roe or Brown in their larger social settings so that it might be possible to appreciate the political dynamics of feminism and protest or the struggle for racial justice that impinged upon the legal process. On his terms, legal change is nothing more than the playing out of a legalistic game of analogical reasoning, with victory going to the analogically fleet and agile of mind. The pernicious effect of such a formulation is that legal change is not thought of as part of a sociopolitical process nor as even a pragmatic response to changing historical conditions. Instead, it is viewed solely as the culmination of the internal and irresistible force of legal reasoning. Notwithstanding many formalists' opinions to the contrary, it is surely unpardonable for lawyers and law professors to present themselves as the exclusive architects of legal and social change. To portray the development of legal doctrine as being brought about largely by dint of analogical reasoning is both dangerous and self-serving; dangerous because it trivialises the vital role of popular struggle and selfserving because it conveniently portrays academics as the saviours of social justice. On the contrary, analogical reasoning is mere prelude or postscript to a political letter. 
Legal change is as much about political action as it is about making good legal arguments. Decisions like Brown and Roe become 'fixed poi nts' in the shifting constitutional universe not because they are legally correct or analytically sound, but because they are considered politically valid and socially acceptable. The difference between Plessy v Ferguson $^{8}$ and Brown has nothing to do with interpretive cogency or hermeneutical integrity i $\mathrm{n}$ constitutional doctrine; analogical reasoning was not a decisive factor. It has everything to do with changing currents and concerns in the political context that frame and condition such germinal and disruptive judicial decisions. Plessy ceased to be a fixed point on the constitutional compass because it no longer enjoyed sufficient political confidence and public support; its perception as having an analytically weak or analogically suspect status was beside the historical point. Rightness was a matter of social policy and political persuasion, not constitutional law. Indeed, without abandoning his cherished attachment to analogical reasoning and the discredited doctrine of stare decisis, Sunstein would have been hard pressed to recognise Brown as a sound or correct legal decision in the summer of 1954. Like many other jurists, he would be thrown on the painful horns of the perennial formalist dilemma-either he would have to renounce his legal faith if he was to maintain his political bel iefs or he could hold fast to his legal faith and accept the law's reactionary and, in that case, racist ethos.

\section{Incomplete agreements}

While it might well be the case that 'to argue from one factual situation and 
to decide by analogy is a natural tendency of the human and legal mind, ${ }^{9}$ it is not the be-all-and-end-all of law and it most certainly is not the hallmark of legal practice that distinguishes it from moral, political or ideological contestation. Indeed, it is only one part of law's repertoire of argumentative moves. Moreover, far from being insulated from large-scale moral controversies, analogical reasoning gains its intellectual purchase and practical efficacy by virtue of its resort to social and political values. Sunstein reluctantly concedes this, but insists that incompletely theorised agreements function as 'foundations for both rules and analogies' (p 6). Such agreements allow judges to ground particular outcomes in something more substantial than their own legal instincts, but less demanding than a fully thought out theory or consensus for their political convictions; 'while people diverge on some relatively high-level proposition, they might be able to agree when they lower the level of abstraction' ( $\mathrm{p}$ 37). By reference to such mid-level artefacts, he defends his claim that the legal arena does and should stand separately from any political involvement. Accordingly, as well as being pragmatically useful, incompletely theorised agreements allow judges to get on with their task without having to take a definitive or Hercu lean stand on deep political or moral values.JO In this way, Sunstein's championing of incompletely theorised agreements not only serves to explain how judges reach particular outcomes, but also illuminates the hallmark of a wellfunctioning legal system because they are 'an important source of social stability and ... enable people to live together to permit them to show each other a measure of reciprocity and mutual respect' (pp 5 and 39). 
Sunstein is quick to admit that, on occasion, disagreements can be desirable and incompletely theorised agreements can run the risk of reaching an outcome that is 'mistaken' ( $\mathrm{p} \mathrm{58)}$ in situations where there may be widespread agreement about general value-judgements, but the agreement is nevertheless incompletely theorised. This, of course, prompts the query of why this outcome must be considered 'mistaken' and on what basis it might be possible for judges to subject incompletely theorised agreements to 'scrutiny and critique' (p 59). Sunstein acknowledges that it would be foolish to deny that some general theories sometimes get it right, and even more foolish to suggest that incompletely theorised agreements warrant respect whatever their content: 'except in unusual situations and for multiple reasons, general theories are an unlikely foundation for judge-made law, and caution and humility about general theory are appropriate for courts, at least when multiple theories can lead in the same direction' (p 59). While this could be interpreted as meaning that he is doing away with any foundation to legal reasoning at all, it is more reasonable to assume that he is merely replacing one foundation with another. Besides being the stuff of what good legal decisions comprise, incompletely theorised agreements are positioned to become Sunstein's contribution to the formalist task of determining 'the crucial part of the lawyer's distinctive solution to social pluralism' (p 59).

For Sunstein, the need to make the system work on a daily basis is of paramount importance; efficacy is treasured more than consistency or candour. Indeed, he makes the telling suggestion that, where judges have conflicting political frameworks, what is left unsaid can be as important as 
what is said and that judges should keep silent so as to facilitate agreement on outcomes in particular cases; 'silence on something that may prove false, obtuse, or excessively contentious can help minimise conflict, allow the present to learn from the future, and save a great deal of time and expense' ( $\mathrm{p}$ 39). On the other hand, Sunstein also maintains that if judges ... have actually agreed on a general theory, and if they are really committed to it, they should say so' (p 44). One could be forgiven for asking how judges could ever know they had reached agreement on such general theories in the first place, if they took Sunstein's vow of silence. Perhaps Sunstein also wondered about this when he later concludes that, 'in law, as in politics, disagreement can be a productive and creative force, revealing error, showing gaps, moving discussion and results in good directions' (p 58). While this assessment seems to the jurisprudential point, it is an odd statement for someone who is committed to demonstrating that judges can resolve 'large, contested issues of social life' in a distinctly legal way rather than 'only on ... a sectarian basis' (p 42).

Even if one accepts Sunstein's claim that incompletely theorised agreements can come to the rescue of analogical reasoning, he is still left with severe problems to overcome. For instance, in Sunstein's world, two judges may appeal to the same or different principles in order to energise analogical reasoning, but, so long as they both lead to the same outcome, there is no cause for concern. It does not matter why fact pattern $\mathrm{X}$ and $\mathrm{Y}$ are deemed analogous; all that matters is that the dispute is resolved. Indeed, Sunstein worries that any attempt to explain what general theory was decisive 
might jeopardise the result. However, in this case, incompletely theorised agreements are less facilitating adjudication and more concealing the actual basis of each judge's decision. While one judge may view A as the relevant characteristic, another may hold B to be. If, however, the justification for why $\mathrm{X}$ and $\mathrm{Y}$ are held to be analogous is ignored, there is no possibility for predicting whether $\mathrm{L}$ or $\mathrm{M}$ may also be analogous. Stare decisis seems to have become so much un necessary baggage in the pragmatic enterprise. Furthennore, a more serious problem wou ld arise when there is no agreement at this more general level. Incompletely theorised agreements can only be possible or viable, if both parties have at least some reason for accepting the result in question. If there is none, the judges are thrown back on their own political instincts. In such circumstances, the reliance upon incompletely theorised agreements as 'foundations for both rules and analogies' ( $p$ 6) seems hopelessly inadequate. As is so often the case, formalist theories run out at the very point where they are most needed.

In many ways, I do not disagree with Sunstein's claim that judges are able to make doctrinal progress by developing incompletely theorised agreements on controversial issues; it is a plausible and sensible account of judicial practice. However, when it is appreciated that Sunstein and I are engaged in very different jurisprudential projects, it is difficult to understand how such an account can advance Sunstein's ambitions. Whereas Sunstein is intent upon arguing that law is a self-sufficient practice that is significantly more 
constrained than political or moral argument and that can generate detenninate and legitimate results, I want to offer a more critical account in which adjudication is one more site to play politics. Consequently, it is only when analogical reasoning is placed within a much broader and more expansive non-formalist account of law and adjudication that the operation of legal reasoning as a practical exercise in decision-making can be fully grasped and appreciated. It is to that task that I briefly tum.

\section{Playing the game}

Efforts to utilise notions of 'game' and 'play' as devices for understanding various aspects of human thought and behaviour have a distinguished philosophical lineage. However, despite general agreement over the relevance and utility of such notions, there has been little agreement on the role and status that games, as it were, play in illuminating the human predicament and advancing its critical analysis. ${ }^{11}$ In entering this longplaying contest, I want to take a very particular strategy and side. The traditional stance towards games and play that passes from Plato through Kant and Schiller to Huizinga and Caillois apprehends them as activities that occur outside and in contrast to reason. Play is a feature of the irrational side of life in which chance is opposed to necessity and is beyond the ken of analytical knowledge; it is undisciplined and represents an arbitrary, unmediated, exuberant, spontaneous, instinctual, chaotic and unbou nded outpouring of emotion. In contrast to this tradition, I want to 
take my lead from the more subversive work of Saussure and Derrida. Rather than treat play as something that is to be set against or distinguished from reason or work, I want to defend an understanding of game-playing that combines both free-play and structure in a dynamic appreciation of the judicial performance in law's continuing game. In particular, I want to argue that, as far as the games of law and adjudication are concerned, it is always the case that play and reason, rules and discretion, and freedom and constraint go hand in hand; these are not so much polar opposites or dichotomies as interdependent parts or forces that both energise and destabilise the adjudicative challenge. In this deconstructive approach, play is treated not so much as irrational, but more as part of what it means to be rational: there is no Reason for settling arguments about reason that are not themselves part of the game of reasoning. $1_{2}$

In a seminal essay, Derrida places the notion of play at the heart of the deconstructive critique and the subversive claim that 'language bears within itself the necessity of its own critique.' $1_{3} \mathrm{He}$ explains how the Western philosophical tradition has driven itself to metaphysical distraction by its insistence on compressing its thinking about the world into the strait jacket of dichotomous opposites chance and necessity, reason and desire, mind and body, etc. In particular, he concentrates on the ill-fated effort in discursive studies to ground the distinction between structure and free-play in 'a fundamental immobility and reassuring certitude ... beyond the reach of free-play.' However, in rejecting the possibility of a structured 
foundation that is privileged over and controls play, Derrida is not suggesting that there is somehow a free-play that happens outside of structure and that itself controls structure. Derrida insists that, in matters of human discourse, there is no question of choosing between, on the one hand, a formalist interpretation the 'dreams of deciphering a truth or an origin which is free from free-play' and, on the other hand, an anti-formalist interpretation the affirmation of a free-play that tries to pass beyond the dream 'of full presence, the reassuring foundation, the origin and the end of the game.' Instead, what must be done is 'to conceive of the common ground and the differance of this irreducible difference.' In other words, the apparent full presence of totalising structure is only made viable and given force by the threatening absence of a disruptive free-play in the same way that the apparent full presence of free-play is only rendered threatening by the pervasive absence of a stultifying structure. As Derrida states:

If totalization no longer has any meaning, it is not because the infinity of a field cannot be covered by a finite glance or a finite discourse, but because the nature of the field that is, language and a finite language excludes totalisation. This field is in fact that of a game, that is to say, a field of infinite substitutions in the closure of a finite ensemble. This field permits these infinite substitutions only because it is finite, that is to say, because instead of being an inexhaustible field ..., instead of bei ng too large, there is something missing from it: a centre which arrests and founds the free-play of substitutions. ${ }^{14}$

In terms of jurisprudence, this deconstructive stance can be put to great and unsettling effect in the non-formalist project. In the adjudicative performance, the structure of rules and the play of discretion interact and feed off each other in the game of legal interpretation: play is the element of the game that disrupts and destabilises the structured rules that constitute the 
game. There is always a tension between order and disorder, freedom and constraint, and determinacy and indeterminacy that cannot be resolved by a totalizing account or performance. For example, it is not possible to think of or understand determinacy without indeterminacy: each plays off the other in the relentless encounter that both makes meaning possible and prevents its ultimate grounding. In this way, determinacy and indeterminacy in legal interpretation can be understood as locked in a relentless historical struggle for dominance that allows only temporary respites, but no final resolution or ultimate balance. Determinacy is only realisable against an informing background of indeterminacy and it is the possibility of determinacy that gives the threat of indeterminacy any bite. Accordingly, legal meaning is a simultaneous mix of the determinate and indeterminate. In Hartian terms, for example, this translates into the acknowledgement that rules will be experienced as having a core of accepted meaning and a penumbra of uncertainty, but the identity of each will shift and change; what was once thought to be at the core will become penumbra! and vice-versa. The relation between core and penumbra cannot be described once-and-for-all: it is a socio-historical artifact and cannot be reduced to a simple formula or overarching narrative. ${ }^{15}$ Whether particular interpretations of a rule are or are not compatible is not the point. It is the fact that the question of their compatibility is always open and contestable.

Both formalists (and their nihilistic critics) overlook the crucial insight that meaning is found in the social interaction of freedom and constraint, not in the privileging of one over the other. Whereas formalists, including the 
pragmatic Sunstein, emphasise the stability and pre-dominance of structured determinacy over the marginalised threat of a disruptive indeterminacy, antiformalists stress the unbounded play of an anarchic indeterminacy over the stabilising force of a orderly determinacy. Both are mistaken. In contrast to formalist claims, law's game of adjudication has no greater (or lesser) legitimacy than that which its participants earn for themselves in their performance and play. As practised by its mainstream operatives, legal theory exists as a kind of a grand narrative or meta-discourse that is produced by the discourse of law to validate its own status as a scientific discourse in the sense that it possesses an objectivity and foundation that lies outside itself and whose evaluative standards are adequacy, accuracy and Truth itself. In short, jurisprudence exists to legitimate the rules of its own game. However, there is no metalanguage or one way of playing the game that is intrinsically or extrinsically capable of grounding and validating the conclusions reached or the justifications used. ${ }_{6}^{16}$ Legitimacy and, therefore, justice is not achieved by judicial conformity to a set way of proceeding, but is something that can only arise from within the adjudicative game itself and be generated by the participants' own discursive practices and institutional interactions. The correctness of any particular move is established through persuasion and argument, not proof or demonstration; the difference between 'good' and 'bad' moves is game-specific and must be judged within the game, even as the rules are being reinterpreted. Legitimacy, therefore, is something that does not precede or ground any judgment given, but something that follows or flows from the rhetorical force of the judgment made. 
Whereas formalist jurisprudence seeks closure and legitimacy by privileging the passing as the permanent, anti-formalist efforts are too ready to dismiss the fact that the adjudicative performance can only be made sense of as an exercise in rule application rather than as an unbounded exercise in judicial free-play. Nevertheless, this concession does not undermine the pragmatic claim that the adjudicative performance is an entirely fluid and contingent game in which 'anything might go'. While law is a game that is defined by and through its enabling rules, it is a game in which everything is always a move in the game and in which there is no way to make a move that is not itself a move in the game. As an activity that it always beyond absolute determination and never fully finished, adjudication not only passively allows, but also actively encourage transformative and disruptive acts because, without them, the game risks paralysis and irrelevance: 'the novelty of the unexpected "move" . . can supply the system with that increased performativity it forever demands and consumes.' 17 In this way, the adjudicative game is played both within and with the rules that constitute it as a game; the limits of the game and the validity of acceptable moves within any particular performance of the game are not established once-and-for-all, but are provisional markers that are constantly being negotiated and re-negotiated as the game plays on. What counts as a move within the game is a part of the game, not apart from it.

In this deconstructive understanding, there are two aspects to play indeterminacy and decision. Law's language game is a vast practice of almost infinitely possible moves in which each player must come to a 
decision as to which move to make. The moment and nature of the decision made cannot be grounded in anything outside itself; there is no possibility of an a contextual metric for closure. As Derrida puts it, 'the moment of decision, as such, must be the consequence or effect of this theoretical or historical moment, of this reflection or this deliberation, since it always marks the interruption of the juridicoor ethicoor politicocognitive deliberation that precedes it, that must precede it.' 18 In simple jurisprudential terms, the decision is never entirely explainable by or reducible to the rule(s) of which it claims to be an application. A particular performance or move cannot be detached from the general game itself each can only be fully appreciated in the context of the other. It is the subject or player that both occupies and fills the gap between the game's indeterminate possibilities and the determinate decision made. As such, judges do not stand astride the game, but are altered and shaped by the game's limits as they play to re-construct those limits; they are influenced by the present contours of the game as they influence the game's continuing performance and possibilities. In formalist terms, there is no final or enduring span between the game's general indeterminacy and particular decisions that is not destabilised by the constituted and constituting identity of the different players: indeterminacy 'is not simply a moment to be overcome by the occurrence of the decision, ... [but] continues the decision and the latter does not close itself off from the former.' ${ }_{19}$ Politics is always present and irrepressible because general indeterminacy both gives arise to and continues to permeate the particular 
decision made.

By understanding the move from general indeterminacy in this way, it should be clear why my approach is pragmatic as opposed to either formalist or anti-formalist. It resists the conclusion that any decision is valid simply because it is a decision; the idea that there is complete freedom to decide makes no sense at all because it is only within a structure of constraints, albeit thoroughly contingent and revisable in content and direction, that decision-making can be comprehended as decision-making. Without some formative structure or informing context, there would be no game as a process of human engagement and reflection, but only a random collision of thought-less movements. Indeed, the very notion of choice implies a constrained context that identifies what is and is not being chosen between. At the very least, a decision has to possess an important element of cognition, even if the ultimate decision is to make an arbitrary choice. Moreover, the choice is not, as anti-formalists suppose it to be, between an ultimate rational grounding or a free-floating irrational grunt: this is only to re-install the idea of universal Reason and another false dichotomy between reason and non-reason. There are grounds of and for decisions, but they are contingent and unstable: reasons can be given as to why one decision is better than another, but these arguments are never themselves guaranteed or vouchsafed outside the context of argument. Consequently, legal reasoning is about the moves that are presently in play and which structure law's reasoning game in such a way as to enable choices between competing definitions of particular rules in light of their 
general indeterminacy. However, while providing an argumentative context for reasoning and definition, these moves are themselves being contingently re-worked. As such, the rules of the reasoning game do not so much constrain or cabin judges' room for manoeuvre as make it possible and operational.

Legal reasoning, therefore, is primarily a practical activity, not an abstract and arcane meditation on legal intelligence. Like most practical skills, it is acquired by the experience of doing it and handed down from practitioner to practitioner: it is about 'knowing the ropes'. Legal reasoning is not a series of fonnulaic applications in an abstract space, but a functional engagement in real time; it is not a philosophical reflection, but a practical activity; it not a logical operation, but an exercise in operational logic. However, although it is primarily an activity, it does not mean that it does not have a basic structure nor that there are no basic guidelines to follow. Legal reasoning, therefore, refers as much to an attitude or style of argument as to the techniques of argument themselves. On these matters, I am in general agreement with Sunstein. However, unlike Sunstein, I maintain that a good legal argument has no essential hallmark that fixes it as 'good' outside of its particular context. This explains why a good legal decision one day might be considered unconvincing at a later time. This fact, of course, means that the 'soundness' of any particular episode of legal reasoning is to be adjudged in terms of its capacity to persuade other judges and lawyers in a particular community at a particular time rather than its analytical approximation to some logical ideal of argument; the fact that Brown is treated as a better legal decision than Plessy 
is about its political value and acceptability, not its inherent argumentative force and cogency. As such, therefore, while Sunstein rightly depicts legal reasoning as comprising a repertoire of arguments that combine to sustain a culture of legal reasoning, he fails to accept that those arguments and that culture are themselves politically dynamic and not the stabilising force that he and other neo-pragmatists insist. In this way, law and legal reasoning are treated as not so much tools or databanks, but comprise performative activities in the game of adjudicative interpretation.

\section{Beyond craft}

The traditional skills and techniques of the judicial craft are central to the performance of this rhetorical practice. Nonetheless, while the learned knack of using legal materials with adroitness and dexterity is not to be underrated, the effect of such a limited depiction of lawyers' special and distinctive expertise is that it can too easily be used to avoid the democratic responsibility of justifying their power and authority by reference to the realworld pressure of getting the job done. For example, Sunstein defends a modest version of professional craft as the learned ability to make intuitive judgements about fixed points in the legal universe and to fathom ways to render them consistent enough to let legal reasoning proceed. Apart from its formalist underpinnings, this account glosses over the more ambitious claims made for it. By insisting that good lawyering must tum on a regimen of restraint and restriction in which 'a set of practices, conventions, and outcomes ... sharply constrains legal judgment' (p 13), Sunstein turns 
lawyering into an inward-looking and insular profession. This depiction of the judicial craft artificially and unnecessarily cuts law and adjudication off from the sustaining political context and rich historical resources from which they gain their vigour and conscience with which they achieve their highest democratic calling. Legal artistry demands more than technical proficiency: political ideals must and do combine with professional discipline in the best and most compelling performances of law's adjudicative game.20

When judges begin to understand themselves as rhetorical participants in law's infinite language game, they become less troubled by law's incorrigible indeterminacy and adjudication's openness. Indeed, disabused of the formalist project's appeal, they might come to embrace those features rather than resist them. In particular, once it is fully accepted that law is a game of infinite possibilities, judges might abandon the beliefs that law and adjudication are closed and determinate practices and that openness and indeterminacy are to be feared. Of course, this does not mean participants are free to do as they wish. They are always participating within their extant context which they must struggle to change as they play within its constraints. However, once aware of the constructive nature of the boundaries, judges and jurists might realise that it is less about looking and more about seeing. When it comes to law and adjudication, it is people's vision that constrains them, not the legal materials. In this sense, change is as much a matter of imagination as anything else. However, such a realisation does not lead into the clutches of the discredited anti-formalists. Pragmatic judges will appreciate that, 
like pragmatic philosophers, their positive task 'is to fecundate [their] analytical skills with dreams and to discipline [their] dreams with analysis.' In striving to do this, judges will work with and through the rules, but there will be no governing manual of rules: there is only the continuing responsibility to dream and experiment in reasonable and reasoned ways. And, of course, there are 'no rules and regulations for dreaming reasonable dreams. $\cdot 21$

In going about this experimental work, judges will take a characteristically pragmatic attitude towards the meaning and merit of past decisions; they recognise that another way of understanding the past is to imagine a better future for the present. Whereas formalist judges and jurists are conservative in the sense that they respect historical continuity for its own sake and treat the doctrinal past as the primary source of future enlightenment, pragmatic judges seek to make a critical accommodation with the legal tradition by combining heresy and heritage in a playful judicial style. As such, judges should consider themselves neither formalistically bound to perpetuate the wisdom of past decisions nor instrumentally free to craft future decisions; they work the present space between the past and the future. In the experimental spirit of a pragmatic critique, they might take seriously Holmes' aphorism that 'continuity with the past is only a necessity, not a duty. ${ }^{12}$ So informed, they might begin to push through on the implications of the pragmatic insight that history and its situated reason are not a foundation on which to build, but a resource-site from which to draw: earlier decisions possess no free-standing or self-justifying precedential value, but must continually earn their spurs afresh through dint of 
their contemporary pertinence to new problems and contexts. Neither historical longevity nor contemporary newness has particular valence in fashioning present solutions to future problems. Understood in this non-formalist way, judges will be entitled to be most satisfied with themselves and their work when they are praised not only for the legal soundness of their work, but also for the inventiveness and boldness of their proposals. Whereas the formalist mind is 'of a doctrinaire and authoritative complexion: the phrase must be is ever on its lips,' a pragmatic judge is more 'a happy-go-lucky anarchistic sort of creature' who recognises both the appeal and responsibility of experimentation. 23 Paying attention to context and distrusting broad generalities, they must be conscious of their imagination's limitations and guard against both the formalist tendency to translate personal insight into universal truth and the anti-formalist willingness to resign themselves uncritically to their ideological intuitions. Pragmatist judges do not have a license for whimsy or caprice, but a responsibility to do the best that they can in difficult circumstances there is and can be no better way.

Within this pragmatic frame of reference, the qualities of the great judicial players in law's language game are not so different to those that are exhibited by judges that are traditionally acknowledged as part of law's judicial pantheon. While good judges are lauded for their technical abilities in parsing cases and rooting out inconsistencies, great judges are celebrated for their vision and inventiveness: 'dealing with great tasks as play ... is a sign of greatness. ${ }^{24}$ Those judges that take most seriously the experimental imperative are those that flaunt conventional 
standards in the process of re-formulating them; their judgments are the exceptions that prove the rule. Indeed, some of the great judges of the common law tradition, like Benjamin Cardozo in the United States, Alfred Denning in England, Lionel Murphy in Australia and Bertha Wilson in Canada, are precisely those who refuse to be hampered by customary habits of judicial mind. For instance, the lasting attraction of Learned Hand's (in)famous judgment in Carroll Towing 'the barge owner's duty ... is a function of three variables: (I ) The probability that she will break away; (2) the gravity of the resulting injury, if she does; (3) the burden of adequate precautions. Possibly, it serves to bring this notion into relief to state it in algebraic terms: if the probability be called $P$; the i njury, $L$; and the burden, $B$; liability depends on whether $B$ is less than $L$ multiplied by P: i.e., whether $B<P L^{\prime} 25$ is not to be found in the substantive wisdom of the decision and the fact that he did or did not get it right. Instead, from a pragmatic perspective, its canonical quality ought to be found in the playful example that he set by giving other judges the courage to follow their own experimental convictions.

What makes Holmes, Cardozo, Denning, and Wilson into great judges is much the same as what makes George Best, Dick Fosbury, Mohammed Ali and Olga Korbut into great players: it is not whether they somehow got it right, but that they played with a panache, a style that caught the imagination and changed people's understanding of what it means to play the game. By making novel moves, they play the game as much with the rules as within the rules. Such pragmatic judges recognise that law is not something to be 
mastered, but is an infinite game of transformation in which experimentation and improvisation are valued above predictability and faithfulness to existing rules and ideas of what it is to play the game. At its most audacious, this style of judging demands 'the willingness to stay in play, stay with the flux, without bailing out at the last moment. . . [and] in keeping alive that indefiniteness, that possible-who-knows-when, may be-soon, maybe-now, that sense of working on thin ice, without assurance, keeping the play in play, keeping the exposure to the abyss in play, without arresting or tranquillizing it.'26 When played by technically skilled and imaginatively gifted players, legal reasoning is neither a hubristic effort to bring the game to a perfect end nor an irresponsible attempt to foment chaos; it is an infinitely variable process in which there is never any ultimate victory or performance, but only the repeated and unrepeatable working of the space between order and chaos, freedom and constraint, and permanence and contingency.

\section{Conclusion}

In this essay, therefore, I have sought to show that it is well past time to abandon Chief Justice Coke's claim that there is an 'artificial Reason and Judgment of Law which requires long Study and Experience before a Man can attain to the Cognizance of it.' This is a self-serving myth of lawyers, judges and jurists that cannot be sustained as a descriptive truth or a prescriptive claim and one to which Sunstein unwittingly contributes. While it is true that proficiency in legal reasoning, as with all other kinds of reasoning, is something that is attained through 'long study and experience', 
legal reasoning is not something that stands outside that practice, that disciplines that practice, or that has an independent existence from it. There is nothing more (or less) to legal reasoning than the practice of doing it. Again, like other kinds of reasoning, it is only 'artificial' in that it is not given, but is produced by the craft of its practitioners; it is elaborated, constituted and changed through its contingent performance. Accordingly, the point of my critique has not been to pin down some essential truths about legal argument, but to understand better the playful practice of adjudication as its own political practice and not as a reflection or embodiment of something else. I maintain that this can be done by treating law's language as a deconstructive game of philosophical improvisation that captures 'change, movement, action, continuance, unlimited and unending possibility. $\cdot 21$

The beauty of such a non-formalist pragmatic approach is that it can both recognise the way in which the game of adjudication is presently constituted by these particular manoeuvres and, at the same time, accept that the game of adjudication might come to be re-constituted by a transformed or entirely different set of manoeuvres. The central claim, therefore, is not that law and adjudication are reducible to this or any other set of game-defining rules, but that some set of game-defining rules are in play that, however contingently and temporarily, ensure that judicial players are both bound and free at one and the same time. Within such a jurisprudential scenario, there are at least two important insights that distinguish my non-formalist position from the pseudo-pragmatism of Sunstein that there is no argument that brings debate and disagreement to an end by sheer force of its own universal and cogent 
force, and that there are no arguments whatsoever that do not owe their existence and force to a particular context. What it means to get something 'right' is nothing more (and nothing less) than that a combination of argumentative moves manages to persuade certain people for certain purposes at a certain time and place of their persuasive merit. In law as so much else, it's all in the game. 


\section{Notes}

1. E. H. Levi, An Introduction to Legal Reasoning (Chicago: University of Chicago Press, 1949) 73.

2 For a fuller account of this ambitious claim, see A. Hutchinson, It's Alt in the Game: A NonFoul 1datiol lal Accoum of Lnw. Politics and Adjudication (forthcoming, 1998).

3 For a general survey, see M. Brint and W. Weaver (eds), Pragmmism in Lnw and Sociery (Boulder: Westview Press, 1991); and 'Symposium: The Renaissance of Pragmatism in American Legal

4 Thought' (1990) 63 S Cal LRev 1569.

4 This is what John Austin labelled 'the competition of opposing analogies'. See J. Austin. Lecrures On Jurisprudence (London: J. Murray, 5th ed, 1885) 653 and I030.

5 Sec n 1 above, 2 and 104. See also Warner, 'Three Theories of Legal Reasoning' (1989) 62 S Cal L Rev 1523, 1552-1556.

6 D. Kennedy, 'Legal Education and the Reproduction of Hierarchy' in D. Kairys (ed), The Politics of Law (New York: Pantheon Books, 1982) 47.

7 Brown v Board of Education (1954) 347 US 483; and Roe v Wade (1973) 410 US 113.

8 Plessy v Ferguson (1896) 163 US 537.

9 Mcloughlin v O'Brial1 [1983] AC 410, 419 per Lord Wilberforce.

10 See R. Dworkin, Law's Empire (Cambridge, Mass: Belknap Press, 1986). Sunstein also draws a comparison between incompletely theorised agreements and Rawls' idea of 'overlapping consensus'. See J. Rawls, Political liberalism (New York: Columbia University Press, 1993) 133-172.

11. For a critical survey of this Judie tradition, sec M. Spariosu, Diollysus Reborn: Play and the Aesthetic Dimension in Modem Philosophical and Scie111ific Discourse (Ithaca, New York: Cornell University Press, 1989).

12 While this broadly deconstructive approach to life, games and law holds considerable promise, it must be emphasised that, in depicting law as being constituted by the tension between structure and play, the ambition is not to privilege play at the expense of structure. Those that simply want to invert the relation and privilege play over structure,remai $n$ trapped within the very system they claim to subvert and reject: a studied 'anything goes' that pits Dionysian free-play against Apolline ruledness is simply the flip side and, therefore, the conti nuation of the traditionalist stance. See, for example, P. Feyerabend, Against Method (New York: Verso. 1975).

13 J. Derrida, 'Structure, Sign, and Play in the Discourse of the Human Sciences' in R. Macksey and E. Donato (eds), The Structuralist Controversy (Baltimore: Johns Hopkins Press, 1970) 254.

14 ibid 248, 264-265, 265 and 260.

15 See HL.A. Hart, The Concept of Law (Oxford: Clarendon Press, 2nd ed, 1994). For a fuller account of this dynamic relation, see A. Hutchinson, 'A Postmodern·s Hart: Taking Rules Sceptically' (1995) 58 MLR 783.

16 See J-F. Lyotard and J-L. Thibaud, Just Gaming (Minneapolis: University of Minnesota Press, 1985) 28 and 43

17 J-F. Lyotard, The Postmodern Condition: A Report on Knowledge (Manchester: Manchester University Press, 1984) 15. See, also, S. Fish, Doing What Comes Naturally (Durham, NC: Duke University Press, 1989) 355-358.

18 J. Derrida, 'Force of Law: The Mystical Foundation of Authority' in D. Cornell et al (eds), Deconstruction And the Possibility of Justice (New York: Routledge, 1992).

19 J. Derrida, 'A Response' in C. Mouffe (ed), Deconstruction and Pragmatism: Simon Critchley, Jacques Derrida, Ernesto Laclau, and Richard Rorty (London: Routledge, 1996) 87.

20 See Hutchi nson, n 15 above, 815-817. The reference to 'political ideals' is, of course, to be understood in a pragmatic way: no particular results or consequences necessarily follow from the adoption of such a commitment and there is no one tried-and-true programme for political action because politics itself is always contestable and can never be a privileged grou nd for anything. Once a pragmatic critique becomes doctrinaire or programmatic, it ceases to be pragmatic.

21 S. Rosen, The limits of Analysis (New York: Basic Books, 1980) 260.

22 O.W. Holmes, Collected Legal Papers (New York: Harcourt, Brace, 1920) 270

23 W. James, Pragmatism (Indianapolis: Hackett Publishing Company, 1981) 124.

24 'Ecco Homo' in F. Nietzsche, The Philosophy of Nietzsche (New York: The Modern Library, 1954) 853.

25 US v Carroll Towing Co (2d Cir. 1947) 159 F.2d 169.

26 J. Caputo, Radical Hermeneutics: Repetition, Deconstruction aizd the Hermeneutic Project (Bloomington: Indiana University Press, 1987) 198-199.

27 H. Baker, Jr, Blues Ideology and Afro-American Lileralure: A Vernacular Theory (Chicago: University of Chicago Press, 1984) 8. 